\title{
Braking Torque Compensation Strategy and Thermal Behavior of a Dual Three-Phase Winding PMSM During Short-Circuit Fault
}

\author{
P. Giangrande ${ }^{1}$, V. Madonna ${ }^{1}$, S. Nuzzo ${ }^{1,2}$, C. Gerada ${ }^{1}$, M. Galea ${ }^{1,3}$ \\ ${ }^{1}$ Power Electronics, Machines and Control Group, University of Nottingham, Nottingham, UK, p.giangrande@nottingham.ac.uk \\ ${ }^{2}$ Department of Engineering Enzo Ferrari, University of Modena and Reggio Emilia, Modena, Italy \\ ${ }^{3}$ School of Aerospace, University of Nottingham Ningbo, China
}

\begin{abstract}
Permanent magnet synchronous machines (PMSMs) employing the dual three-phase winding represent a suitable solution for complying with the reliability requirements typically needed in safety-critical applications. Their inherent fault-tolerant capability allows to operate the system (e.g. electro mechanical actuator or traction drive-train), even after the occurrence of a three-phase short-circuit in one winding set. Nevertheless, an appropriate post-fault control strategy is indispensable for preventing the PMSM performance derating. In this work, the design of a dual three-phase PMSM, intended for aerospace application, is presented. The PMSM performance is evaluated via finite element (FE) analysis, in both healthy and three-phase short-circuit conditions. A post-fault control strategy aimed at balancing the braking torque is then discussed. Since the implemented strategy is based on the current overload of the healthy winding, the temperature rise is experimentally investigated on the PMSM prototype. The thermal analysis verifies the compensation strategy feasibility, by proving that the thermal overload does not have a major effect on the wire insulation lifetime.
\end{abstract}

Keywords - Dual Three-Phase Winding, PMSM, Thermal Analysis, Three-Phase Short-Circuit, Post-Fault Control Strategy.

\section{INTRODUCTION}

High-power density and excellent efficiency are indisputable benefits revealed by conventional three-phase PMSMs [1-3]. These features make them widely appealing in applications, where high performance and low weight represent very stringent design constraints [4-6]. However, when a winding failure occurs, the moving permanent magnets (PMs) continue to induce voltage in the armature winding and the resulting current is source of uncontrolled thermal overload, which may lead to critical damages (e.g. PM demagnetisation) [7, 8]. Hence, an accurate thermal management is also required [9].

To exploit the PMSMs' advantages and improve their availability, dual three-phase winding PMSMs are often proposed as a viable option [10-12]. These machines employ a multiphase structure consisting of two sets of three-phase winding, which are wound on the same stator core [13]. The described configuration allows to achieve the reliability requirements demanded in safety-critical applications, such as electro mechanical actuators (EMAs) [14-17] and electric propulsion systems for vehicles, locomotives and ships [18-21]. The enhanced availability is not the only benefit arising from the adoption of dual three-phase PMSMs. In fact, as the mechanical power is achieved by employing two sets of winding, lower rating semiconductor switches can be used for the power

Part of this work was funded by the INNOVATIVE doctoral programme. The INNOVATIVE programme is partially funded by the Marie Curie Initial Training Networks (ITN) action (project number 665468) and partially by the Institute for Aerospace Technology (IAT) at the University of Nottingham. This project has received funding from the Clean Sky 2 Joint Undertaking under the European Union's Horizon 2020 research and innovation programme under grant agreements no. 807081 and no. 821023 . electronics converters (PECs) [22]. In addition, the efficiency is improved, due to the reduced copper losses compared to an equivalent three-phase PMSM [13].

In literature, several analyses regarding the fault-tolerant capability of dual three-phase PMSMs, can be found [23-25]. In [23] and [24], the machine behaviour is investigated in case of three-phase open-circuit fault. In [24], when a PEC fault occurs, the winding connected to it is purposely open (i.e. the connection between PEC and winding is interrupted), while the healthy winding is still supplied. The resulting torque shortfall is supplemented by increasing the current flowing through the healthy winding and its thermal overload capability is studied. In [25], the performance of dual three-phase PMSM working with one set of short-circuited winding is considered. In particular, output torque and torque ripple are analysed for several winding arrangements. However, the thermal behaviour of both healthy and faulty windings is not examined.

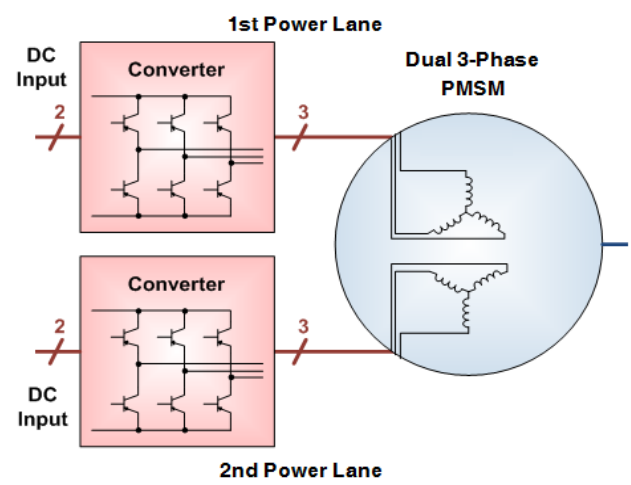

Fig. 1. Architecture of the electric drive for dual three-phase PMSM.

In this work, the analysis of a dual three-phase winding PMSM designed for aerospace EMA applications is addressed. The implemented electric drive architecture is sketched in Fig. 1, where two independent PECs fed as many winding sets (i.e. dual power lane). Each winding set is designed for the application's full power rating, differently from the most common option of sizing the winding sets for half of the rated power [24, 25]. The chosen approach allows to generate the rated torque also during active-open operations (i.e. only one winding set is supplied at rated current, whereas the other is open), without compromising the machine performance. The PMSM behaviour is evaluated via FE analysis at different operating conditions, such as active-active (i.e. both sets of winding fed with half of the rated current), active-open and active-shorted (i.e. one winding set is powered, whilst the other is short-circuited). For the latter 
operating mode, a compensation strategy is proposed aiming at balancing the braking torque. The resulting overcurrent inevitably leads to a thermal overload, which might drastically compromise the wire insulation lifetime [26]. Therefore, thermal tests are finally performed on the available PMSM prototype during the post-fault strategy implementation to prove the feasibility of such a compensation technique.

\section{Designed DuAl ThreE-Phase PMSM}

According to the EMA specifications, the electrical machine is required to deliver $1 \mathrm{Nm}$ at $2500 \mathrm{rpm}$ and operate at a maximum ambient temperature of $70^{\circ} \mathrm{C}$ using natural air cooling system. The machine operates with a short-time duty-cycle, since the EMA operating time does not exceed $30 \mathrm{~s}$ (i.e. time necessary for completing the mission profile). Due to the safety-critical nature of the application under study, a dual three-phase winding PMSM is selected to ensure an adequate level of availability and to comply with the weight constraint (i.e. mass $\leq 2.5 \mathrm{~kg}$ ). The 12 slots / 10 poles configuration is identified as suitable combination after a preliminary trade-off study. In fact, it provides high self-inductance and very low mutual inductance, which confine the short-circuit current and minimise the magnetic coupling between healthy and faulty windings [25, 27]. Taking into account the above mentioned weight constraint, a single-layer concentrated winding is chosen to achieve a good slot fill factor and relatively short end-windings, which allow to minimize both the copper losses and the PMSM axial length [8, 28]. Additionally, this winding arrangement guarantees a better isolation among the phases, reducing the probability of phase-to-phase faults. The two winding sets are star-connected with independent neutral points (i.e. the neutral points are electrically insulated), whilst the shift angle between phase 'A1' and phase 'A2' axes is null.

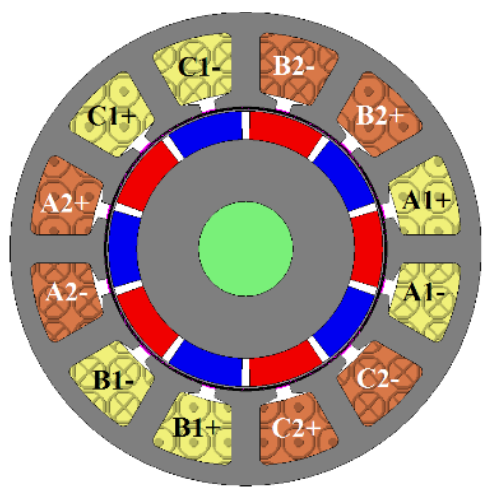

Fig. 2. Geometry and winding layout of the designed dual three-phase PMSM.

TABLE I. DUAL THREE-PHASE PMSM PARAMETERS

\begin{tabular}{|c|c|c|}
\hline Parameter & Symbol & Value \\
\hline Rated Speed [rpm] & $\Omega_{\text {PMSM }}$ & 2500 \\
\hline Rated Torque $[\mathrm{Nm}]$ & $\tau_{\mathrm{PMSM}}$ & 1 \\
\hline Rated Current $\left[\mathrm{A}_{\mathrm{rm}}\right]$ & $\mathrm{I}_{\mathrm{n}}$ & 2.2 \\
\hline Phase Resistance $[\Omega]$ & $\mathrm{R}$ & 5.24 \\
\hline d-axis Inductance $[\mathrm{mH}]$ & $\mathrm{L}_{\mathrm{d}}$ & 11.3 \\
\hline $\mathrm{q}$-axis Inductance $[\mathrm{mH}]$ & $\mathrm{L}_{\mathrm{q}}$ & 11.3 \\
\hline PM Flux [Wb] & $\Psi_{\mathrm{PM}}$ & 0.043 \\
\hline Stack Length $[\mathrm{mm}]$ & $\mathrm{L}$ & 60 \\
\hline Stator Outer Diameter $[\mathrm{mm}]$ & $\mathrm{D}_{\mathrm{o}}$ & 50 \\
\hline Airgap Thickness $[\mathrm{mm}]$ & $\mathrm{g}$ & 1 \\
\hline Wire Thermal Class $\left[{ }^{\circ} \mathrm{C}\right]$ & $\theta_{\text {class }}$ & 180 \\
\hline
\end{tabular}

In terms of materials, a silicon-steel alloy (i.e. M270-35A) is used for both stator laminations and rotor back iron. This alloy shows a good compromise between saturation flux density value (i.e. $1.7 \mathrm{~T}$ ) and market price. The PMs mounted on the rotor surface are made of samarium-cobalt, which reveals higher temperature stability than neodymium-iron-boron. A carbon fiber retaining sleeve is utilized for holding the PMs on the 17-4 PH stainless steel shaft and protecting them during the assembling stage (PMs are mechanically brittle). Finally, an aluminium housing fitted with radial fins is employed for enhancing the heat dissipation by natural convection. Most of the features described above can be observed in Fig. 2, where the cross-section of the designed PMSM is depicted, while a summary of the machine parameters is provided in Tab. I. The next sections deal with the performance analysis of the PMSM via a purposely-built FE model, showing the relevant results and considerations.

\section{PMSM FE ANALYSIS}

Before analysing the machine behaviour under a three-phase short-circuit fault occurring in one of the winding sets, it is of worth to predict the machine performance under healthy conditions. In this section, therefore, the no-load and full-load operations of the PMSM described in Section II are examined through the implementation of a purposely-built FE model.

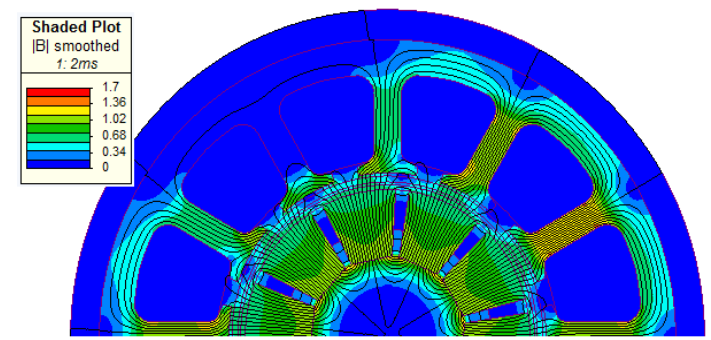

Fig. 3. No-load flux density map and flux lines distribution at $2500 \mathrm{rpm}$.

\section{A. No-load performance}

The no-load performance is evaluated with the terminals of the machine armature windings open-circuited. In such condition, only the PM contribution is present: the flux density map and the flux lines distribution at the rated speed of $2500 \mathrm{rpm}$ are reported in Fig. 3.

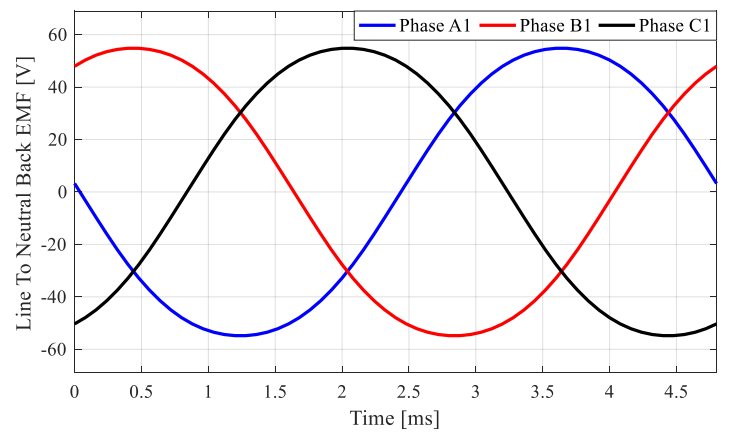

Fig. 4. Back-EMF waveforms at $2500 \mathrm{rpm}$ for one three-phase winding.

The induced voltage in the armature windings at no-load, also called back-electromotive force (back-EMF), is determined through the FE model. Due to the zero shift angle between the two winding sets, only the back-EMFs induced in one three-phase winding are shown in Fig. 4. The outcome of the FE simulation at no-load is used for computing the voltage constant and the total harmonic distortion (THD), that are equal to $0.016 \mathrm{~V}_{\mathrm{rms}} / \mathrm{rpm}$ and $4.7 \%$ respectively.

\section{B. Load performance}

The PMSM performance, at on-load and in healthy conditions, is discussed here. Two operating modes are considered: 1) the active-active mode, which consists in supplying both windings with half of the rated current (i.e. $\left.\mathrm{I}_{\mathrm{n}} / 2=1.1 \mathrm{~A}_{\mathrm{rms}}\right)$ and 2 ) the active-open mode, where one winding 
set is open-circuited, whereas the other one is fed with $I_{n}$ (i.e. $\left.2.2 \mathrm{~A}_{\mathrm{rms}}\right)$. By running the PMSM in active-active mode, lower copper losses compared to the active-open mode are obtained. In fact, both windings (in which $\mathrm{I}_{\mathrm{n}} / 2$ flows) equally contribute to the torque generation. Thus, in terms of efficiency, this is the more beneficial approach for developing the required torque. On the other hand, the active-open mode is mainly recommended for post-fault operations. Indeed, when a fault affects the PEC, it allows to operate the PMSM with the same average torque as in the pre-fault case (i.e. the active-active mode). For both the described operating modes, the flux density maps and the flux lines distributions are presented in Fig. 5.

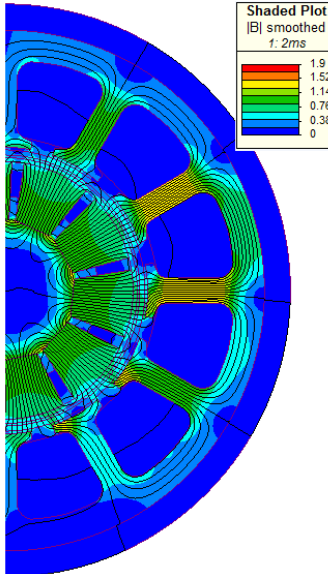

(a)

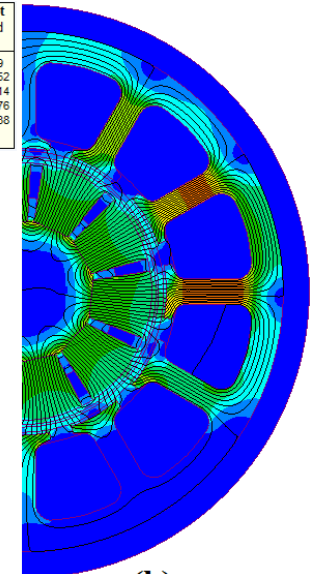

(b)
Fig. 5. Flux density map and flux lines distribution for $1 \mathrm{Nm}$ at $2500 \mathrm{rpm}$ during (a) active-active and (b) active-open operating modes.

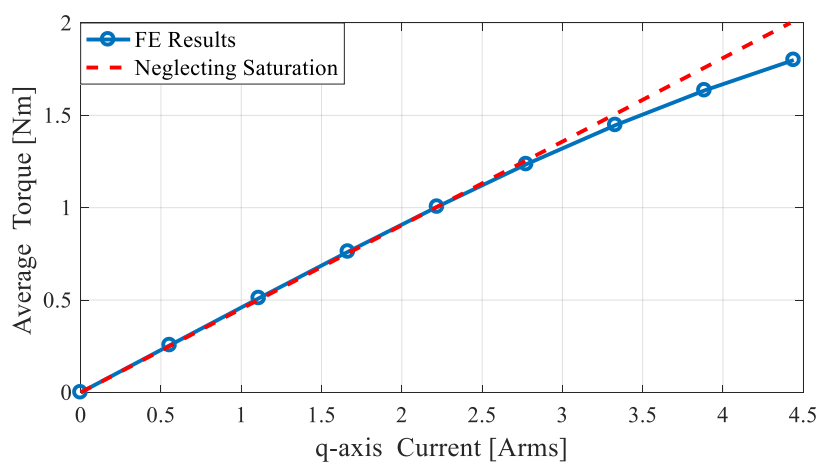

Fig. 6. Torque vs. $q$-axis current curve with (blue) and without (red) magnetic saturation, during active-open operating mode.

From Fig. 5, it can be observed how a higher saturation level is registered in the stator tooth during the active-open mode (see Fig. 5.b), as expected. This circumstance is a direct consequence of the larger electric load. In order to check the PMSM saturation level during active-open operation, the torque-current characteristic is determined by FE simulations, for several $q$-axis current values up to twice $\mathrm{I}_{\mathrm{n}}$ (i.e. $4.4 \mathrm{~A}_{\mathrm{rms}}$ ). The obtained results are summarised in Fig. 6. For $q$-axis currents lower than $2.2 \mathrm{~A}_{\mathrm{rms}}$, the saturation influence on the developed torque is negligible (i.e. linear region), whereas it becomes appreciable for values above $I_{n}$ (i.e. mismatch between red and blue lines in Fig. 6). In the linear region of the torque-current curve, the PMSM torque constant is equal to $0.45 \mathrm{Nm} / \mathrm{A}_{\mathrm{rms}}$. Given that each winding set is designed for delivering $1 \mathrm{Nm}$, the rated torque can be produced by operating in both the active-active and the active-open modes, without thermally stressing the wire insulation. In addition, such a design choice does not increase the PEC design-cost, due to the relatively low PMSM rated power (i.e. $262 \mathrm{~W}$ mechanical power).

\section{3-PhASE SHORT-CiRCUIT AND COMPENSATION STRATEGY}

In Section III, the no-load and on-load performance of the considered PMSM have been evaluated. Also, the active-active and the active-open operating modes have been discussed, analysed and compared via FE investigations. In this section, the PMSM behaviour during the three-phase short-circuit of one winding (i.e. active-shorted operating mode) is considered, along with the post-fault compensation strategy.

\section{A. Performance during three-phase short-circuit fault}

The PMSM performance in active-shorted mode is examined by determining the braking torque and the amplitude of the short-circuit current at steady-state for several rotor speeds, using the FE model. The braking torque trend from 0 to $2800 \mathrm{rpm}$ (i.e. the $112 \%$ of $\Omega_{\mathrm{PMSM}}$ ) is shown in Fig. 7 . The maximum absolute value of braking torque is equal to $-0.623 \mathrm{Nm}$ and it is reached at $900 \mathrm{rpm}$. Further, a braking torque of $-0.39 \mathrm{Nm}$ is developed at rated speed. The results relative to the amplitude of the steady-state short-circuit current vs. mechanical speed are reported in Fig. 8.

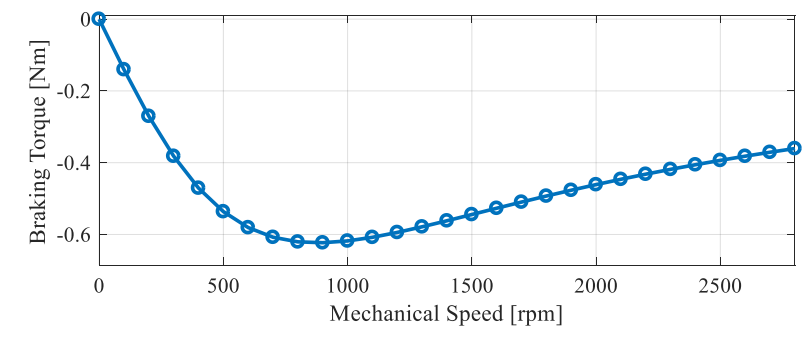

Fig. 7. Braking torque characteristic (FE results).

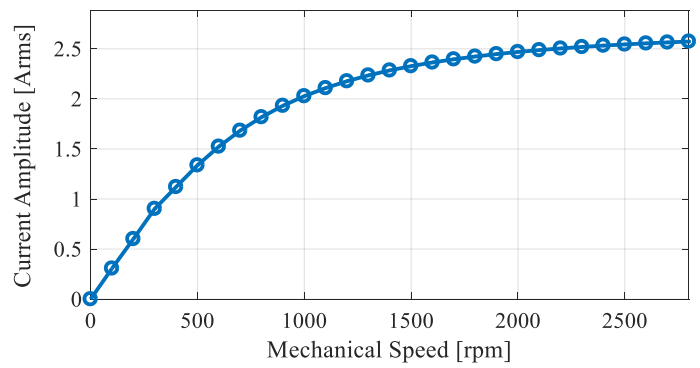

Fig. 8. Amplitude of the short-circuit current at steady-state (FE results).

It can be noticed that, at $2500 \mathrm{rpm}$, a current of $2.54 \mathrm{~A}_{\mathrm{rms}}$ flows through the faulty winding when this is experiencing a three-phase short-circuit fault. Both Fig. 7 and Fig. 8 prove the fault-tolerant capability of the designed PMSM. In fact, the braking torque and the short-circuit current at rated speed are respectively $39 \%$ and $115 \%$ of the corresponding rated values. As highlighted in the previous section, an appropriate post-fault strategy, in response to a PEC fault, is represented by the active-open operating mode [24, 25]. However, this strategy loses its effectiveness in the occurrence of short-circuit winding fault. Indeed, although the connection between PEC and winding is interrupted, the faulty winding is still supplied by the induced back-EMFs, due to the moving PMs. The resulting short-circuit current might lead to PM demagnetisation and severe torque oscillations. These issues become particularly evident in case of asymmetric faults (i.e. inter-turns and phase-to-ground faults). For this reason, it is common practice to intentionally induce a symmetric fault (i.e. three-phase short-circuit) after an asymmetric fault detection [29]. Therefore, the occurrence of any short-circuit winding fault leads to operate in the active-shorted mode for the dual three-phase PMSM at hand. This results in a deterioration of the available torque at the PMSM's shaft, caused by the braking torque (see Fig. 7). To 
overcome the torque shortfall, the $q$-axis current of the healthy winding is increased as post-fault strategy.

\section{B. Post-fault compensation strategy}

Using the FE model, the required $q$-axis current values for balancing the braking torque are determined for different short-circuit speeds. The obtained results are provided in Fig. 9.

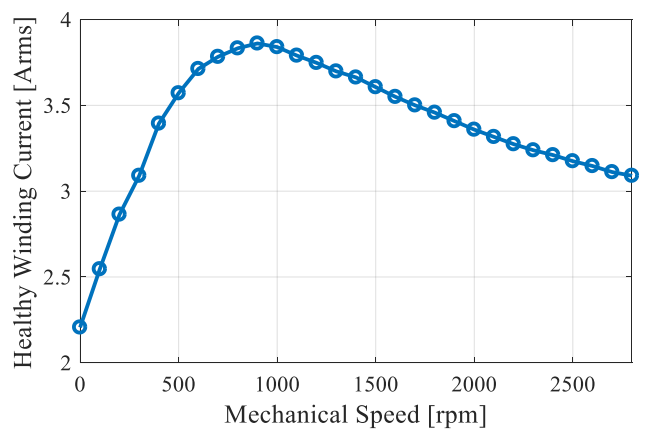

Fig. 9. $q$-axis current required by the compensation strategy.

According to Fig. 9, a $q$-axis current of $3.17 \mathrm{~A}_{\mathrm{rms}}$ (i.e. $144 \%$ of $I_{n}$ ) is needed at rated speed, while $3.86 \mathrm{~A}_{\text {rms }}$ (i.e. $175 \%$ of $I_{n}$ ) are necessary at the speed corresponding to the maximum absolute value of braking torque (i.e. $900 \mathrm{rpm}$ ). The relatively high current values demanded by the presented compensation strategy imply that the PECs must be designed for handling such a current overload, in order to succeed in the post-fault strategy. The compensation strategy validity is proven by means of FE simulations, analysing two faulty conditions: 1) short-circuit at $900 \mathrm{rpm}$ (i.e. largest compensation current) and 2) short-circuit at $2500 \mathrm{rpm}$ (i.e. greatest short-circuit current). Considering the short-circuit at $900 \mathrm{rpm}$, Fig. 10 shows the torque (top sub-plot) and the phase currents in both windings (middle and bottom sub-plots) for the operating conditions listed below.
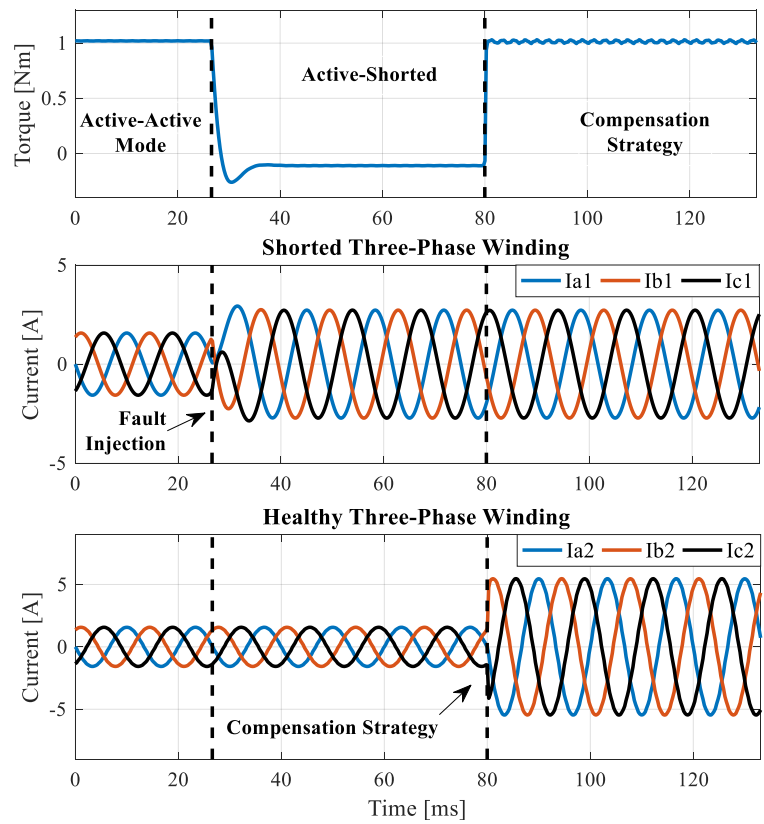

Fig. 10. PMSM operations at $900 \mathrm{rpm}$ during pre-fault and post-fault (with and without compensation strategy): a) torque (top sub-plot), b) phase currents in the faulty winding (middle sub-plot) and c) phase currents in the healthy winding (bottom sub-plot).

- Active-active mode - both windings are fed with $\mathrm{I}_{\mathrm{n}} / 2$ and the PMSM delivers $1 \mathrm{Nm}$ until the fault injection.

- Active-shorted mode with no compensation - at $26.4 \mathrm{~ms}$, a three-phase short-circuit is induced in one winding, while the current in the other is kept equal to $1.1 \mathrm{~A}_{\text {rms. Hence, }}$. from $26.4 \mathrm{~ms}$ to $80 \mathrm{~ms}$, the PMSM works in active-shorted mode with no compensation strategy. During the post-fault transient, the peaks of both torque and current amount to $-0.26 \mathrm{Nm}$ (i.e. the $26 \%$ of $\tau_{\mathrm{PMSM}}$ ) and $2.07 \mathrm{~A}_{\mathrm{rms}}$ (i.e. the $94 \%$ of $\mathrm{I}_{\mathrm{n}}$ ) respectively. Instead, the torque at the PMSM shaft and the current through the faulty winding are respectively equal to $-0.11 \mathrm{Nm}$ (i.e. the $11 \%$ of $\tau_{\mathrm{PMSM}}$ ) and $1.93 \mathrm{~A}_{\mathrm{rms}}$ (i.e. the $87.7 \%$ of $\mathrm{I}_{\mathrm{n}}$ ) at steady-state.

- Active-shorted mode with compensation - at $80 \mathrm{~ms}$, the compensation strategy is implemented by increasing the current in the healthy winding from $1.1 \mathrm{~A}_{\text {rms }}$ to $3.86 \mathrm{~A}_{\text {rms }}$. This allows to re-establish the output torque at its rated value, with a ripple of $1.68 \%$. Finally, the PMSM keeps working in active-shorted mode with the compensation strategy on, from $80 \mathrm{~ms}$ to $133 \mathrm{~ms}$.
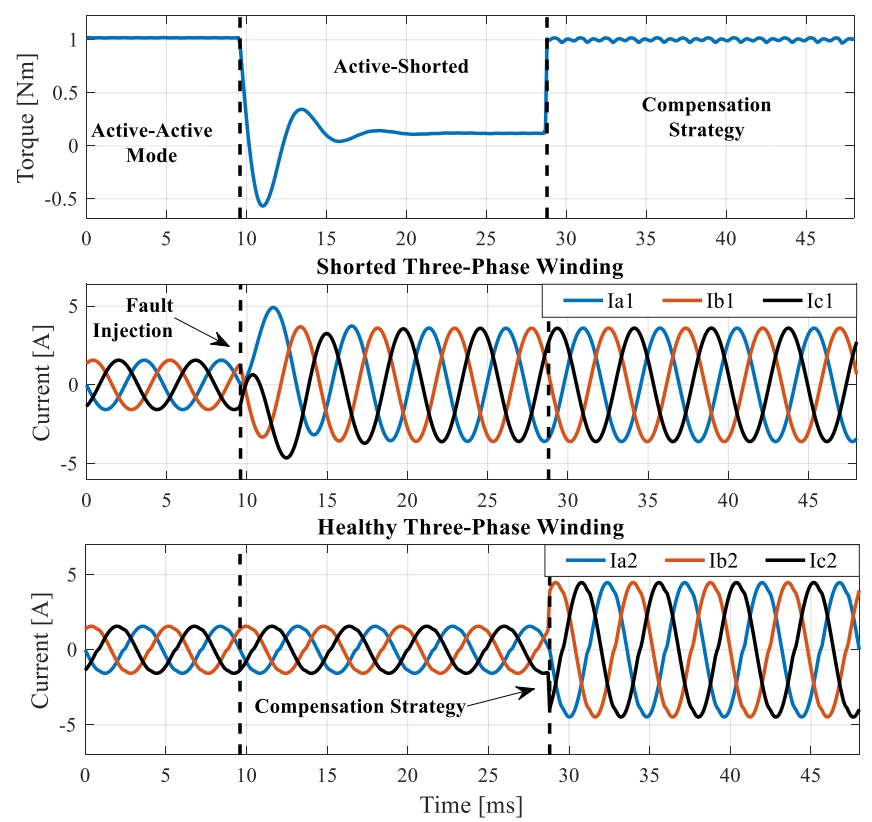

Fig. 11. PMSM operations at $2500 \mathrm{rpm}$ during pre-fault and post-fault (with and without compensation strategy): a) torque (top sub-plot), b) phase currents in the faulty winding (middle sub-plot) and c) phase currents in the healthy winding (bottom sub-plot).

The same FE simulation is performed for a three-phase short-circuit occurring at rated speed and the obtained results are summarised in Fig. 11. The fault is injected at $9.4 \mathrm{~ms}$ and the resultant torque (at steady-state) is equal to $0.12 \mathrm{Nm}$ (i.e. the $12 \%$ of $\left.\tau_{\mathrm{PMSM}}\right)$, during active-shorted mode without compensation strategy. At $28.7 \mathrm{~ms}$, the post-fault strategy is applied by increasing the current from $1.1 \mathrm{~A}_{\mathrm{rms}}$ to $3.17 \mathrm{~A}_{\mathrm{rms}}$ in the healthy winding. As consequence, $1 \mathrm{Nm}$ torque is available at the PMSM shaft, however featuring a deteriorated torque ripple of $2.52 \%$. The presented study highlights that the $175 \%$ of $I_{n}$ (i.e. $3.86 A_{r m s}$ ) is necessary to compensate the braking torque in the worst-case scenario. This significant current overload requires a detailed thermal analysis, which is the next section's topic.

\section{Thermal AnALYSIS AND EXPERIMENTAL RESUltS}

The feasibility of the compensation strategy is subordinated to the influence of the thermal overload on the wire insulation lifetime. Indeed, the winding temperature should not exceed the wire insulation thermal class (i.e. $180^{\circ} \mathrm{C}$ ). Lifetime shortening, can occur quite drastically since $10^{\circ} \mathrm{C}$ increase in winding temperature halves the wire insulation lifetime [30]. For each operating mode considered (i.e. active-active, active-open and 
active-shorted), the thermal behaviour of the PMSM prototype is experimentally evaluated. The winding temperatures are measured by means of $6 \mathrm{~K}$-type thermocouples installed on each phase end-winding (i.e. winding hot-spot) [31, 32] and their values are acquired using a data logger. The worst-case ambient temperature condition (i.e. $70^{\circ} \mathrm{C}$ ), for the application under study, is accounted by performing the thermal tests, while the PMSM prototype is placed inside the environmental chamber, as depicted in Fig. 12.

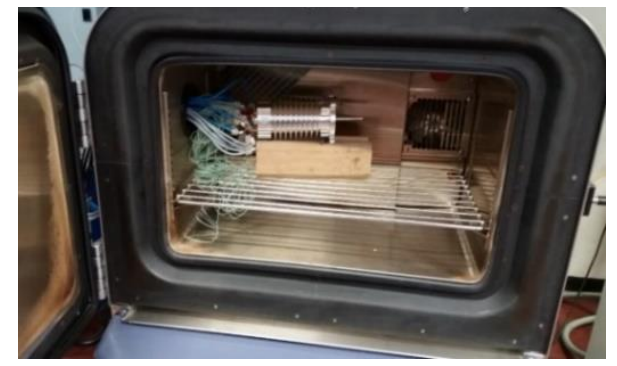

Fig. 12. Experimental setup for the thermal tests: PMSM equipped with thermocouples and placed inside the enviromental chamber.

During the thermal tests, the phases belonging to the same three-phase winding are connected in series (i.e. hereafter series-connected arrangement), with the aim of applying the same thermal stress to all the phases. Further, the operating modes are emulated by feeding each series-connected arrangement with a separate DC power supply, which provides the DC current value correspondent to the RMS value of the operating mode under analysis. It is worth to mention that the use of a DC current does not allow to take into account the influence of the iron losses on the winding temperature. Nevertheless, this does not compromise the measurements, since the amount of iron losses is small compared to the copper losses (proven by the FE analysis, but not shown in the paper), due to the relatively low rated speed of the PMSM prototype. As prescribed by the application requirements, the PMSM prototype is naturally air cooled throughout the thermal analysis. Firstly, the two less thermally challenging operating modes are investigated, namely the active-active and the active-open modes. Considering the former mode, both the series-connected arrangements are supplied with $1.1 \mathrm{~A}_{\mathrm{DC}}$ and the measured temperatures are reported in Fig. 13. The steady-state temperature is not reached, since the thermal study is focused only on a $30 \mathrm{~s}$ time-window, as required by the application's operating time (i.e. EMA operating time does not exceed $30 \mathrm{~s}$ ). In Fig. 13, also after $1000 \mathrm{~s}$ in active-active mode, the winding temperatures (i.e. $107^{\circ} \mathrm{C}$ average) are well below the wire insulation thermal class (i.e. $180^{\circ} \mathrm{C}$ ).

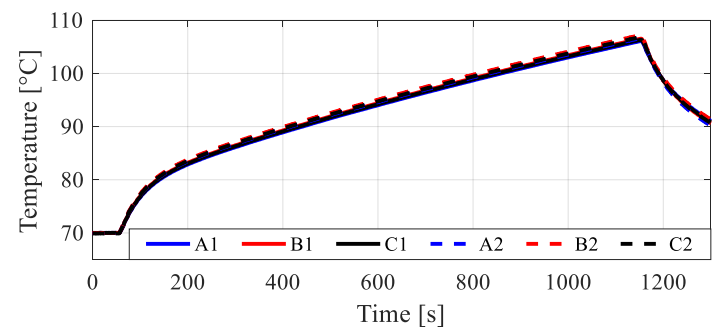

Fig. 13. Temperature profiles measured in active-active operating mode.

For the active-open operating mode, one series-connected arrangement is fed at $2.2 \mathrm{~A}_{\mathrm{DC}}$, whilst the other is open. The recorded temperatures for all the phases of both the loaded and non-loaded winding sets are shown in Fig. 14. In summary, it can be noticed that, after a time-window of approximatively $1200 \mathrm{~s}$, the average temperature of the fed phases reaches
$160{ }^{\circ} \mathrm{C}$, while $120^{\circ} \mathrm{C}$ average is measured on the no-loaded phases. Thus, both active-active and active-open modes do not represent a source of concern for the PMSM thermal management, as anticipated.

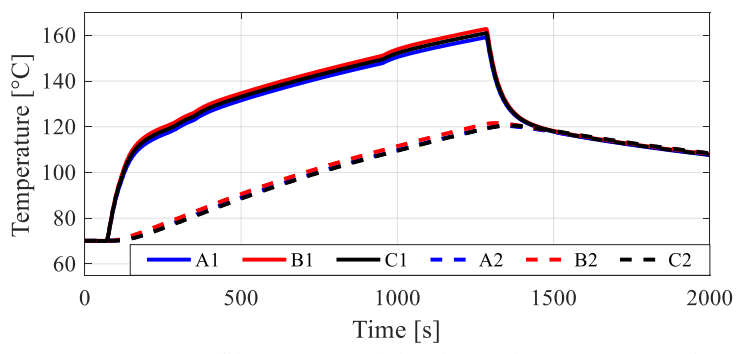

Fig. 14. Temperature profiles measured in the active-open operating mode: loaded (solid lines) and no-loaded (dashed lines) windings.

According to the current values in both faulty and healthy windings, the two most demanding cases are examined for the thermal analysis of the active-shorted operating mode including the compensation strategy implementation. The first considers the three-phase short-circuit at $900 \mathrm{rpm}$, where the highest compensation current is applied, whereas the second analyses the three-phase short-circuit at $2500 \mathrm{rpm}$, which is characterised by the maximum short-circuit current. For the former case, both series-connected arrangements are simultaneously supplied with $1.93 \mathrm{~A}_{\mathrm{DC}}$ (i.e. faulty winding) and $3.86 \mathrm{~A}_{\mathrm{DC}}$ (i.e. overloaded healthy winding) respectively. As reported in Fig. 15, the average temperatures of $102{ }^{\circ} \mathrm{C}$ and $171{ }^{\circ} \mathrm{C}$ are recorded in the faulty and the healthy windings, over an operating time-window of $40 \mathrm{~s}$ (i.e. $10 \mathrm{~s}$ longer than the operating time constraint). These results prove that, despite the significant overcurrent (i.e. $175 \%$ of $I_{n}$ ) resulting from the compensation strategy implementation, the wire insulation lifetime is not affected by the ensuing temperature rise, due to the short-time duty-cycle of the application.

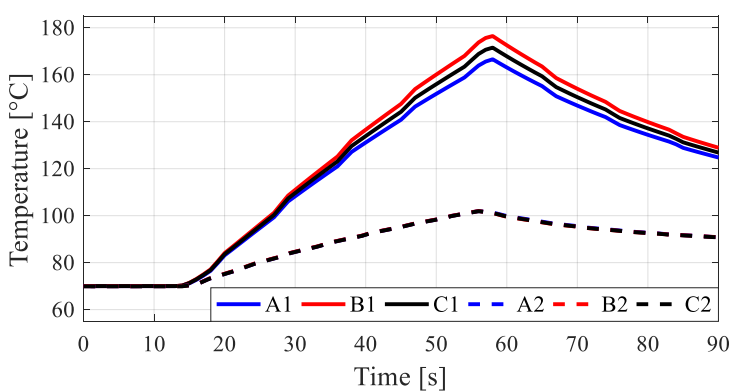

Fig. 15. Temperature profiles measured in the active-shorted operating mode (with compensation strategy) emulating three-phase short-circuit at $900 \mathrm{rpm}$ : healthy (solid lines) and faulty (dashed lines) windings.

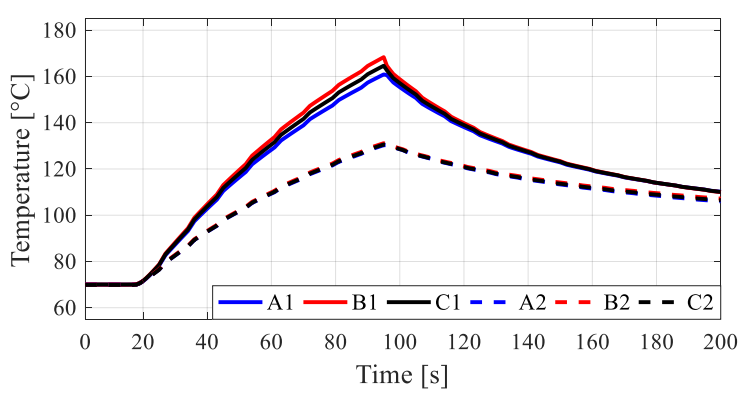

Fig. 16. Temperature profiles measured in the active-shorted operating mode (with compensation strategy) emulating three-phase short-circuit at $2500 \mathrm{rpm}$ : healthy (solid lines) and faulty (dashed lines) windings.

For sake of completeness, the three-phase short-circuit at $2500 \mathrm{rpm}$ is also emulated by feeding (at the same time) the two series-connected arrangements with $2.54 \mathrm{~A}_{\mathrm{DC}}$ (i.e. faulty 
winding) and $3.17 \mathrm{~A}_{\mathrm{DC}}$ (i.e. overloaded healthy winding). The obtained results are illustrated in Fig. 16, where average temperatures of $130{ }^{\circ} \mathrm{C}$ and $165^{\circ} \mathrm{C}$ can be observed in the faulty and the healthy windings respectively, over an operating time-window of approximatively $70 \mathrm{~s}$. Also in this condition, the wire insulation lifetime is not compromised by overcurrent resulting from the adopted compensation strategy.

\section{CONCLUSIONS}

This work presented the performance evaluation of a dual three-phase winding PMSM designed for an aerospace EMA application. The study is carried out through accurate FE simulations of the machine. Apart from the reliability constraints typical of such a safety-critical application, the PMSM design was performed by taking into account a very stringent weight requirement that led to a very compact and light machine topology. Each set of winding was sized for delivering the rated torque, allowing to prevent the performance derating resulting from the adoption of the active-open mode in response to a PEC fault. Special attention was then given to the behaviour of the PMSM during the three-phase short-circuit of one winding set. The post-fault strategy for balancing the braking torque was discussed and its effectiveness was proven via FE, considering both the short-circuit faults at rated speed and at maximum braking torque. Finally, the investigation focused on the thermal analysis of the PMSM prototype, which was made necessary by the overload currents ensuing from the adopted compensation strategy. The winding temperatures were measured during the post-fault strategy implementation, with the PMSM prototype placed inside the environmental chamber. The registered experimental temperature values permit to conclude that, even considering the worst-case scenario of a $175 \%$ current overload, the PMSM is able to complete its mission profile (while compensating the breaking torque), without compromising the wire insulation lifetime.

\section{REFERENCES}

[1] J.F. Gieras, "Permanent magnet motors technology: design and applications", Taylor and Francis, 3rd ed., pp. 612, 2010.

[2] P. Giangrande, V. Madonna, G. Sala, A. Kladas, C. Gerada and M. Galea, "Design and Testing of PMSM for Aerospace EMA Applications," IECON 2018 - 44th Annual Conference of the IEEE Industrial Electronics Society, Washington, DC, 2018, pp. 2038-2043.

[3] A. Al-Timimy, M. Alani, M. Degano, P. Giangrande, M. Galea, and C. Gerada, "Influence of Rotor Endcaps on the Electromagnetic Performance of High Speed PM Machine," in IET Electric Power Applications, Vol. 12, no. 8, pp 1142-1149, 2018.

[4] A. Al-Timimy, G. Vakil, M. Degano, P. Giangrande, C. Gerada, and M. Galea, "Considerations on the Effects that Core Material Machining has on an Electrical Machine's Performance", in IEEE Transaction on Energy Conversion, vol. 33, no. 3, pp. 1154-1163, 2018.

[5] V. Madonna, P. Giangrande, L. Lusuardi, A. Cavallini and M. Galea, "Impact of thermal overload on the insulation aging in short duty cycle motors for aerospace," 2018 IEEE Int. Conf. on Electrical Systems for Aircraft, Railway, Ship Propulsion and Road Vehicles \& International Transportation Electrification Conference (ESARS-ITEC), pp. 1-6, 2018.

[6] A. Al-Timimy, P. Giangrande, M. Degano, Z. Xu, M. Galea, C. Gerada, G. Lo Calzo, H. Zheng, and L. Xia, "Design and Losses Analysis of a High Power Density Machine for Flooded Pump Applications" in IEEE Trans. On Industry Applications, vol. 54, no. 4, pp. 3260-3270, 2018.

[7] V. Madonna, P. Giangrande, A. Walker, and M. Galea, "On the Effects of Advanced End-Winding Cooling on the Design and Performance of Electrical Machines," in XIII International Conference on Electrical Machines (ICEM), pp311-317, 2018

[8] B.A. Welchko, T.M. Jahns, T.A. Lipo, "Fault interrupting methods and topologies for interior PM machine drives", IEEE Pow. Elect. Lett., pp. 139-143, 2004.

[9] Z. Xu, A. Al-Timimy, M. Degano, P. Giangrande, G. Lo Calzo, H. Zhang, M. Galea, C. Gerada, S. Pickering, and L. Xia, "Thermal management of a permanent magnet motor for a directly coupled pump," in International Conference on Electrical Machines (ICEM), pp. 1-6, 2016.
[10] J.W. Bennett, B.C. Mecrow, D.J. Atkinson, et al., "Safety-critical design of electromechanical actuation systems in commercial aircraft", in IET Electric Power Applications, Vol. 5, no. 1, 2011.

[11] C. Sciascera, P. Giangrande, C. Brunson, M. Galea, and C. Gerada, "Optimal design of an electro-mechanical actuator for aerospace application" in Annual Conference of the IEEE Industrial Electronics Society (IECON), pp. 1-6, 2015.

[12] P. Giangrande, V. Madonna, S. Nuzzo and M. Galea, "Design of FaultTolerant Dual Three-Phase Winding PMSM for Helicopter Landing Gear EMA," 2018 IEEE Int. Conf. on Electrical Systems for Aircraft, Railway, Ship Propulsion and Road Vehicles \& International Transportation Electrification Conference (ESARS-ITEC), pp. 1-6, 2018.

[13] M. Barcaro, N. Bianchi and F. Magnussen, "Analysis and Tests of a Dual Three-Phase 12-Slot 10-Pole Permanent-Magnet Motor" in IEEE Trans. on Industry Applications, vol. 46, no. 6, pp. 2355-2362, 2010.

[14] V. Madonna, P. Giangrande, and M. Galea, "Electrical Power Generation in Aircraft: review, challenges and opportunities," IEEE Transactions on Transportation Electrification, vol. 4, pp. 646 - 6591, 2018.

[15] C.I. Hill, S.V. Bozhko, Y. Tao, P. Giangrande, and C. Gerada, "More Electric Aircraft Electro-Mechanical Actuator Regenerated Power Management," in IEEE International Symposium on Industrial Electronics, pp 1-6, 2015.

[16] W. Cao, B.C. Mecrow, G.J. Atkinson, et al., "Overview of electric motor technologies used for MEA", IEEE Trans. Ind. Electron. 2012.

[17] P. Giangrande, F. Cupertino and G. Pellegrino, "Modelling of linear motor end-effects for saliency based sensorless control," in 2010 IEEE Energy Conversion Congress and Exposition, pp. 3261-3268, 2010.

[18] Y. Hu, Z.Q. Zhu, and K. Liu, "Current Control for Dual 3-Phase PM Synchronous Motors Accounting for Current Unbalance and Harmonics" IEEE Jou. of Emer. and Sel. Top. in Pow. Elect., vol. 2, no. 2, 2014.

[19] S.A. Odhano, P. Giangrande, R. Bojoi, and C. Gerada, "Selfcommissioning of interior permanent magnet synchronous motor drives with high-frequency current injection," in 2013 Energy Conversion Congress and Exposition (ECCE), pp. 3852-3859, 2013.

[20] E. Levi, "Multiphase electrical machines for variable-speed applications," IEEE Trans. Ind. Electron., vol. 55, no. 5, pp. 1893-1909, 2008.

[21] F. Cupertino, G. Pellegrino, P. Giangrande, and L. Salvatore, "Model based design of a sensorless control scheme for permanent magnet motors using signal injection," in 2010 Energy Conversion Congress and Exposition (ECCE), pp. 3139-3146, 2010.

[22] Y. Hu, Z.Q. Zhu, and M. Odavic, "Torque Capability Enhancement of Dual Three-Phase PMSM Drive With Fifth and Seventh Current Harmonics Injection," in IEEE Trans. on Ind. Appl., vol. 53, no. 5, 2017.

[23] W. Wang, J. Zhang, M. Cheng, et al., "Fault-tolerant control of dual threephase permanent-magnet synchronous machine drives under open-phase faults," IEEE Trans. Power Electron., vol. 32, no. 3, pp. 2052-2063, 2017.

[24] M. Barcaro, L. Alberti and N. Bianchi, "Thermal Analysis of Dual Threephase Machines Under Faulty Operations," IEEE Symposium on Diagnostics for Electrical Machines, Power Electronics \& Drives, 2011.

[25] M. Barcaro, N. Bianchi and F. Magnussen, "Faulty Operations of a PM Fractional-Slot Machine With a Dual Three-Phase Winding," IEEE Trans. on Ind. Elect., vol. 58, no. 9, pp. 3825-3832, 2011.

[26] C. Sciascera, P. Giangrande, L. Papini, C. Gerada, and M. Galea, "Analytical Thermal Model for Fast Stator Winding Temperature Prediction," in IEEE Transaction on Industrial Electronics, vol. 64, no. 8, pp. 6116-6126, 2017.

[27] V. Madonna, P. Giangrande, C. Gerada, and M. Galea, "Thermal analysis of fault-tolerant electrical machines for aerospace actuators," in IET Electric Power Applications, 2018.

[28] D. Fallows, S. Nuzzo, A. Costabeber and M. Galea, "Harmonic Reduction Methods for Electrical Generation: A Review", in press on IET Generation, Transmission \& Distribution, 2018.

[29] B.A. Welchko, T.M. Jahns, W.L. Soong, et al, "IPM synchronous machine drive response to symmetrical and asymmetrical short circuit faults", IEEE Tran. on Energy Conversion, vol. 18, pp. 291-298, 2003.

[30] C. Sciascera, M. Galea, P. Giangrande, and C. Gerada, "Lifetime consumption and degradation analysis of the winding insulation of electrical machines," in IET International Conference on Power Electronics Machines and Drives, pp 1-6, 2016.

[31] V. Madonna, A. Walker, P. Giangrande, C. Gerada, G. Serra, and M. Galea, "Improved thermal management and analysis for stator end windings of electrical machines," in IEEE Transactions on Industrial Electronics, 2019.

[32] A. Al-Timimy, M. Degano, Z. Xu, G. Lo Calzo, P. Giangrande, M. Galea, C. Gerada, H. Zhang and L. Xia, "Trade-off analysis and design of a high power density PM machine for flooded industrial pump," in 2016 in Annual Conference of the IEEE Industrial Electronics Society (IECON), pp. 1744-1749, 2016. 